\title{
Redirection of Prostaglandin Endoperoxide Metabolism at the Platelet-Vascular Interface in Man
}

\author{
Jacek Nowak and Garret A. FitzGerald \\ Division of Clinical Pharmacology, Vanderbilt University, Nashville, Tennessee 37232
}

\begin{abstract}
Prostacyclin (PGI $)$ is an inhibitor of platelet function in vitro. We tested the hypothesis that $\mathbf{P G I}_{2}$ is formed in biologically active concentrations at the platelet-vascular interface in man and can be pharmacologically modulated to enhance its inhibitory properties. This became feasible when we developed a microquantitative technique that permits the measurement of eicosanoids in successive $\mathbf{4 0}-\mu \mathrm{l}$ aliquots of whole blood emerging from a bleeding time wound.

In 13 healthy volunteers the rate of production of thromboxane $\mathrm{B}_{2}\left(\mathrm{TXB}_{2}\right)$ gradually increased, reaching a maximum of $421 \pm 90$ (mean $\pm S E M) ~ f g / \mu l$ per $s$ at $300 \pm 20 \mathrm{~s}$. The hydration product of $\mathbf{P G I}_{2}$, 6-keto-PGF $1 \alpha$, rose earlier and to a lesser degree, reaching a peak $(68 \pm 34 \mathrm{fg} / \mu \mathrm{l}$ per $\mathrm{s})$ at $168 \pm 23 \mathrm{~s}$. The generation of prostaglandins $\mathrm{PGE}_{2}$ and $\mathrm{D}_{2}$ resembled that of $\mathrm{PGI}_{2}$. Whereas the threshold concentration of $\mathbf{P G I}$ for an effect on platelets in vitro is $\sim 30 \mathrm{fg} / \mu \mathrm{l}$, only $<3 \mathrm{fg} / \mu \mathrm{l}$ circulates under physiological conditions. By contrast, peak concentrations of 6-keto-PGF ${ }_{1 \alpha}$ obtained locally after vascular damage averaged $305 \mathrm{fg} / \mu \mathrm{l}$.

Pharmacological regulation of PG endoperoxide metabolism at the platelet-vascular interface was demonstrated by administration of a TX synthase inhibitor. The rate of production of $\mathbf{P G I}_{2}, \mathbf{P G E}_{2}$, and $\mathrm{PGD}_{2}$ increased coincident with inhibition of TXA, as reflected by three indices; the concentration of $\mathrm{TXB}_{2}$ in bleeding time blood and serum, and excretion of the urinary metabolite, 2,3-dinor- $\mathbf{T X B}_{2}$.

These studies indicate that $\mathbf{P G I}_{2}$ is formed locally in biologically effective concentrations at the site of vessel injury and provide direct evidence in support of transcellular metabolism of PG endoperoxides in man.
\end{abstract}

\section{Introduction}

Prostacyclin $\left(\mathrm{PGI}_{2}\right)^{1}$ is a potent platelet-inhibitory, vasodilator compound in vitro (1), but its circulating concentrations are

Dr. Nowak's present address is Department of Clinical Physiology, Karolinska Institute, Huddinge University Hospital, S-141 86 Huddinge, Sweden.

Address correspondence to Dr. Garret A. FitzGerald, Division of Clinical Pharmacology, Vanderbilt University, Nashville, TN 37232.

Received for publication 3 March 1988 and in revised form 19 August 1988.

1. Abbreviations used in this paper: GC-NICI-MS, gas chromatography-negative ion, chemical ionization-mass spectrometry; $\mathrm{PGI}_{2}$, prostacyclin.

J. Clin. Invest.

(C) The American Society for Clinical Investigation, Inc.

$0021-9738 / 89 / 02 / 0380 / 06 \$ 2.00$

Volume 83, February 1989, 380-385 too low to exert an effect on platelet function or vascular tone under physiological conditions in man (2-5). $\mathrm{PGI}_{2}$ is classified as an autacoid and thought to exert its action close to its site of generation, although quantitative evidence compatible with this concept has yet to be provided. Indeed, such low rates of metabolite formation may merely reflect a relative lack of agonism to its production rather than question the importance of this eicosanoid in the regulation of platelet-vessel wall interactions. In keeping with this hypothesis is the capacity of vascular endothelium to synthesize $\mathrm{PGI}_{2}$, its stimulation by physical and chemical factors associated with vascular perturbation (6-8), and increased excretion of the $\mathrm{PGI}_{2}$ metabolite, 2,3-dinor-6-keto-PGF ${ }_{1 \alpha}$, in human syndromes accompanied by laboratory evidence of platelet activation $(9,10)$.

TX synthase inhibitors represent a potential pharmacological approach to regulation of the formation of arachidonic acid metabolites at the site of platelet-vessel wall interactions in man (11-13). Such compounds dose-dependently inhibit the generation of $\mathrm{TXA}_{2}$, a proaggregatory vasoconstrictor compound, by blocking its formation from the PG endoperoxide substrate, $\mathrm{PGH}_{2}$. Furthermore, it has been demonstrated that endothelial cells can enzymatically use the accumulated platelet endoperoxide as a substrate for $\mathrm{PGI}_{2}$ synthase in perturbed, mixed cell suspensions in vitro $(14,15)$ and that excretion of urinary 2,3-dinor-6-keto- PGF $_{1 \alpha}$ is enhanced after administration of TX synthase inhibitors in man (16). However, the in vitro experiments were performed in the absence of such potentially critical variables as albumin (17) and flow (18), and it is impossible to determine whether the alterations in metabolite excretion reflect events at the platelet-vascular interface or in a tissue with the capacity to synthesize both TXA $_{2}$ and $\mathrm{PGI}_{2}$, such as the lung or the kidney.

To address the hypothesis that eicosanoid formation may be regulated at the platelet-vascular interface in man by administration of a TX synthase inhibitor, we developed methodology that permits their quantitative analysis in successive aliquots of whole blood obtained at the site of a bleeding time wound using a highly specific and sensitive technique, gas chromatography-negative ion, chemical ionization-mass spectrometry (GC-NICI-MS).

\section{Methods}

The blood emerging from a standard template skin incision (16) was collected in successive $40-\mu$ l samples drawn with a pipetman (Oscar Fisher Co., Inc., Newburgh, NY) and added to $200 \mu$ l saline containing heparin ( 0.5 USP unit), indomethacin solution (final concentration 5.5 $\left.\times 10^{-5} \mathrm{M}\right)$ and tetradeuterated standards of eicosanoids (500 pg). The samples were then mixed with $50 \mu 12 \%$ methoxyamine $\mathrm{HCl}$ in aqueous solution and after $30 \mathrm{~min}$ at room temperature the respective methoximes formed were extracted with $1 \mathrm{ml}$ ethyl acetate. The ethyl acetate was subsequently evaporated and the dry samples were treated with acetonitrile, $\alpha$-bromo-2,3,4,5,6-pentafluorotoluene and diisopropylethylamine for $30 \mathrm{~min}$ at room temperature. After evaporation the 
respective methoxime-pentafluorobenzyl esters obtained were separated by TLC. Recovery from the TLC plates was assessed with radiolabeled standards and exceeded 95\%. The derivatization was completed by trimethylsilylation. The quantitative analyses were accomplished using the Nermag R 10-10 mass spectrometer meter coupled to Varian Vista 6,000 gas chromatograph. Chromatography was performed on 10-m fused silica nonpolar capillary column SPB 1 (Supelco, Inc., Bellefonte, $\mathrm{PA}$ ) with the oven temperature of $190^{\circ} \mathrm{C}$ and increasing $20^{\circ} \mathrm{C} / \mathrm{min}$ for $6 \mathrm{~min}$. The mass spectrometer was operated in the negative ion mode with methane ionization at a pressure of $7 \times 10^{-2}$ torr.

Eicosanoid production rates during bleeding time were calculated by dividing the amount of prostanoid recovered in $40-\mu \mathrm{l}$ aliquots of blood by this volume and the individual collection time.

Serum $\mathrm{TXB}_{2}$ was measured using a specific RIA as previously described (19). Urinary excretion of 2,3-dinor-TXB ${ }_{2}$ was by a previously described method using sample purification by immunoaffinity chromatography and analysis by GC-NICI-MS (20).

\section{Results}

Initial experiments were performed to address the pattern and reproducibility of $\mathrm{TXA}_{2}$ and $\mathrm{PGI}_{2}$ formation in bleeding time blood by measurement of their respective hydration products, $\mathrm{TXB}_{2}$ and 6-keto-PGF $\mathrm{F}_{1 \alpha}$. Similar results were obtained when eicosanoids were measured after a bleeding time incision in different arms of the same individual (Fig. 1). While the results were similar in the same individual on different occasions, more variability in the maximal concentrations achieved was evident between volunteers (Figs. 1 and 2). The pattern of formation of both eicosanoids differed substantially. In the group data generation of $\mathrm{TXB}_{2}$ gradually increased, reaching a maximum (mean $\pm \mathrm{SEM}$ ) of $421 \pm 90 \mathrm{fg} / \mu \mathrm{l}$ per $\mathrm{s}(n=13)$ at $300 \pm 20 \mathrm{~s}$. By contrast, the production rate of 6 -keto-PGF $F_{1 \alpha}$ was initially low and then rose to a lower and more variable peak production rate than $\mathrm{TXB}_{2}(68 \pm 34 \mathrm{fg} / \mu \mathrm{l}$ per s). On average this reached a maximum earlier in the bleeding time $(168 \pm 23 \mathrm{~s})$, although in some cases later, transient increases occurred during the course of bleeding. The generation of
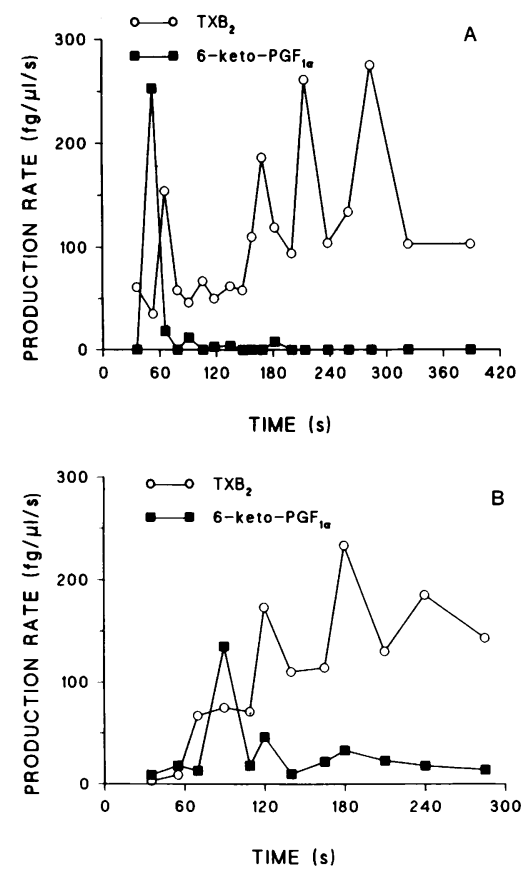

Figure 1. $\mathrm{TXB}_{2}(\mathrm{O})$ and 6-keto-PGF ${ }_{1 \alpha}(\boldsymbol{\square})$ formation $(\mathrm{fg} / \mu \mathrm{l}$ per $\mathrm{s})$ in blood emerging from the bleeding time wound on different occasions $(A$ and $B)$ from the same individual. $\mathrm{TXB}_{2}$ formation increases gradually in the successive $40-\mu$ laliquots of blood while the increase in 6-keto$\mathrm{PGF}_{1 \alpha}$ formation is early and transient.

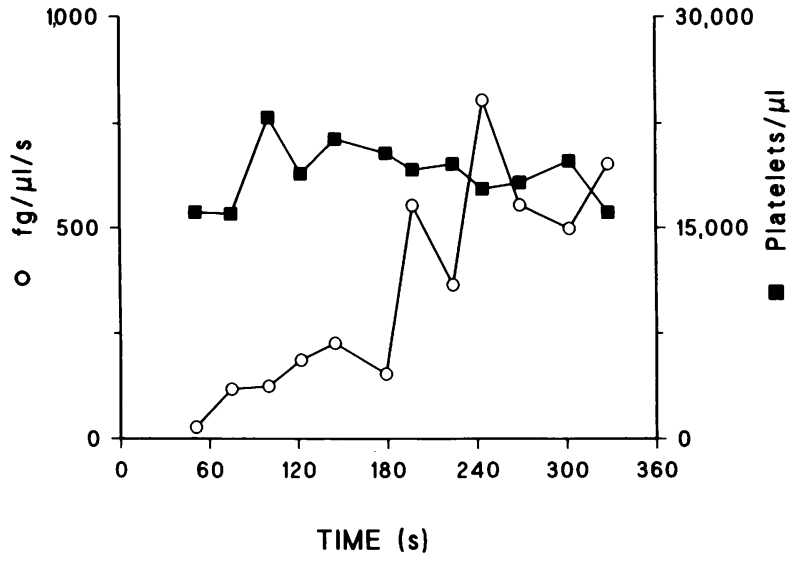

Figure 2. Formation of $\mathrm{TXB}_{2}(0)$ and platelet count ( $(\mathbf{)})$ in blood emerging from bleeding time wound site on a separate occasion in a healthy volunteer. This is a different individual than is depicted in Fig. 1. Note the similar pattern of increase in $\mathbf{T X B}_{2}$ but the difference in maximal concentrations attained between individuals in contrast to the within individual variability depicted in Fig. 1.

$\mathrm{PGE}_{2}$ and $\mathrm{PGD}_{2}$ resembled that of 6-keto-PGF $\mathrm{PG}_{1 \alpha}$ in that there was a phasic rather than a continuous increase in their production rates during the bleeding time. While a contribution to the $\mathrm{TXB}_{2}$ concentrations by $\mathrm{TXA}_{2}$ formation by platelets ex vivo is theoretically possible, this is unlikely. $40-\mu l$ samples were collected continuously into indomethacin from the incision site so visible accumulation of blood on the skin surface was not evident. Furthermore, there was no relationship between the platelet count in bleeding time blood (which remained constant) and the steadily increasing concentrations of $\mathrm{TXB}_{2}$ (Fig. 2). Compared with circulating blood the absolute platelet counts were low in the blood emerging from the wound site. This may have reflected consumption in the hemostatic plug.

To investigate the effects of a TX synthase inhibitor on eicosanoid formation at the platelet-vascular interface, we administered $100 \mathrm{mg}$ of imidazo $(1,5-2)$ pyridine-5-hexanoic acid (CGS 13080; Ciba Geigy Corporation, Summit, NJ) to six healthy male volunteers. This compound selectively inhibits TX synthase and has been previously shown to cause increased excretion of urinary 2,3-dinor-6-keto-PGF ${ }_{1 \alpha}$, coincident with inhibition of $\mathrm{TXB}_{2}$ generation in both healthy volunteers and patients with severe atherosclerosis and evidence of platelet activation (21). Bleeding time eicosanoids were measured before administration of this compound, at a time corresponding to peak drug action ( $1 \mathrm{~h}$ after dosing), and when partial recovery from drug effect would be anticipated (6 h after dosing) (21). Two additional indices of TX generation were measured in addition to $\mathrm{TXB}_{2}$ in bleeding time blood: $\mathrm{TXB}_{2}$ generation in serum and excretion of the urinary TX metabolite, 2,3dinor- $\mathrm{TXB}_{2}$.

TX biosynthesis was reversibly depressed by administration of CGS 13080. The average $\mathrm{TXB}_{2}$ production rate fell from $88 \pm 16 \mathrm{fg} / \mu \mathrm{l}$ per s to $6 \pm 2 \mathrm{fg} / \mu \mathrm{l}$ per $\mathrm{s}(P<0.05) 1 \mathrm{~h}$ after dosing. There was a significant, although incomplete, recovery $6 \mathrm{~h}$ after dosing (Fig. 3). Qualitatively similar results were obtained for this and other eicosanoids whether the data were expressed as production rates or actual concentrations in bleeding time blood (Figs. 3-5). Reversible inhibition of TX formation was also documented by measurement of serum $\mathrm{TXB}_{2}$ and excretion of 2,3-dinor-TXB 2 (Table I). 

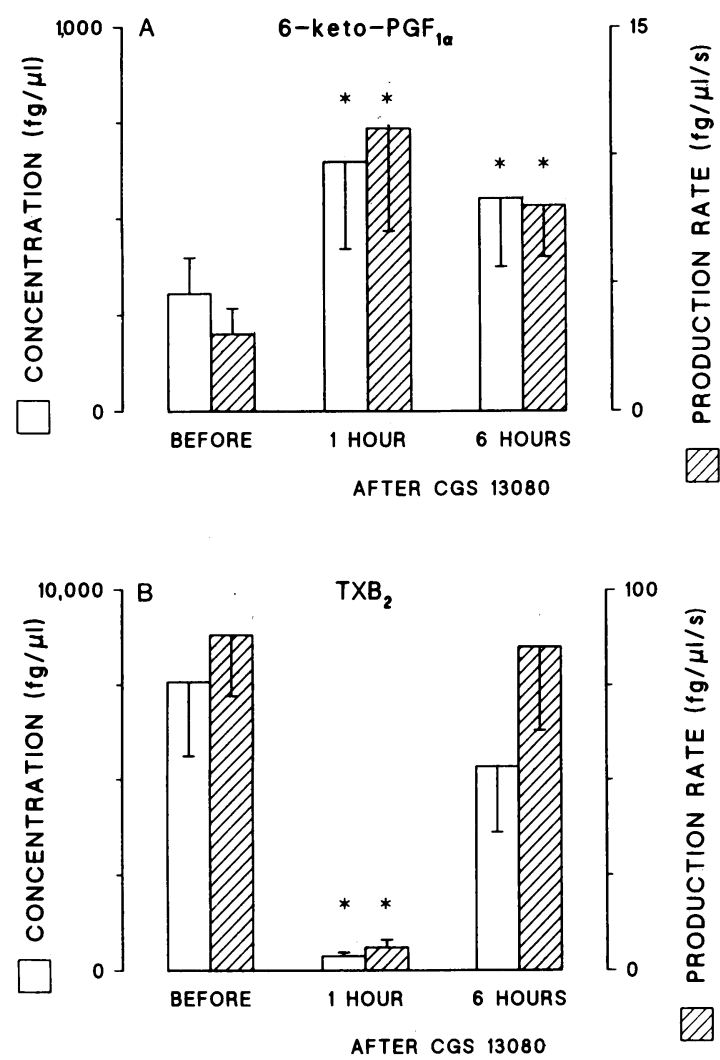

Figure 3. Formation of 6-keto- $\mathrm{PGF}_{1 \alpha}(A)$ and $\mathrm{TXB}_{2}(B)$ in bleeding time blood before and after administration of a TX synthase inhibitor (CGS 13080). Data are expressed both as an absolute concentration and a production rate. Differences from measurements performed before drug administration are indicated as $* *=P<0.01$.

Coincident with depression of TX generation, formation of the other eicosanoids, $\mathrm{PGI}_{2}$ (measured as 6-keto-PGF ${ }_{1 \alpha}$; Fig. 3), $\mathrm{PGE}_{2}$, and $\mathrm{PGD}_{2}$ (Fig. 4), was increased in bleeding time blood. PGF $_{2 \alpha}$ was measured before (both $1 \mathrm{fg} / \mu \mathrm{l}$ per s) and $1 \mathrm{~h}$ after ( 6 and $12 \mathrm{fg} / \mu \mathrm{l}$ per s) administration of the TX synthesis inhibitor in two individuals. Additional evidence that these compounds were formed from platelet-derived endoperoxides was provided by the temporal pattern of formation of these eicosanoids in bleeding time blood (Fig. 6). Thus, after CGS 13080 the pattern of formation of 6-keto- $\mathrm{PGF}_{1 \alpha}, \mathrm{PGE}_{2}$, and $\mathrm{PGD}_{2}$ had converted to resemble the progressive increase with time characteristic of $\mathrm{TXB}_{2}$ under control conditions.

\section{Discussion}

The results of this study provide the first evidence for transcellular metabolism of arachidonate at the platelet-vascular interface in man. They are consistent with the "endoperoxide shunt" hypothesis $(22,23)$. Additional evidence for this phenomenon has been obtained in mixed cell suspensions in vitro $(14,15)$ and includes the increase in urinary 2,3-dinor-6-keto$\mathrm{PGF}_{1 \alpha}$ excretion after TX synthase inhibition in man $(16,21)$. An alternative, or perhaps additional possibility, is that free arachidonate released by platelets might have been used by vascular tissues to augment eicosanoid production (24). The use of GC-NICI-MS rather than RIA $(25,26)$ was critical in this regard as we have previously shown that only minor de-
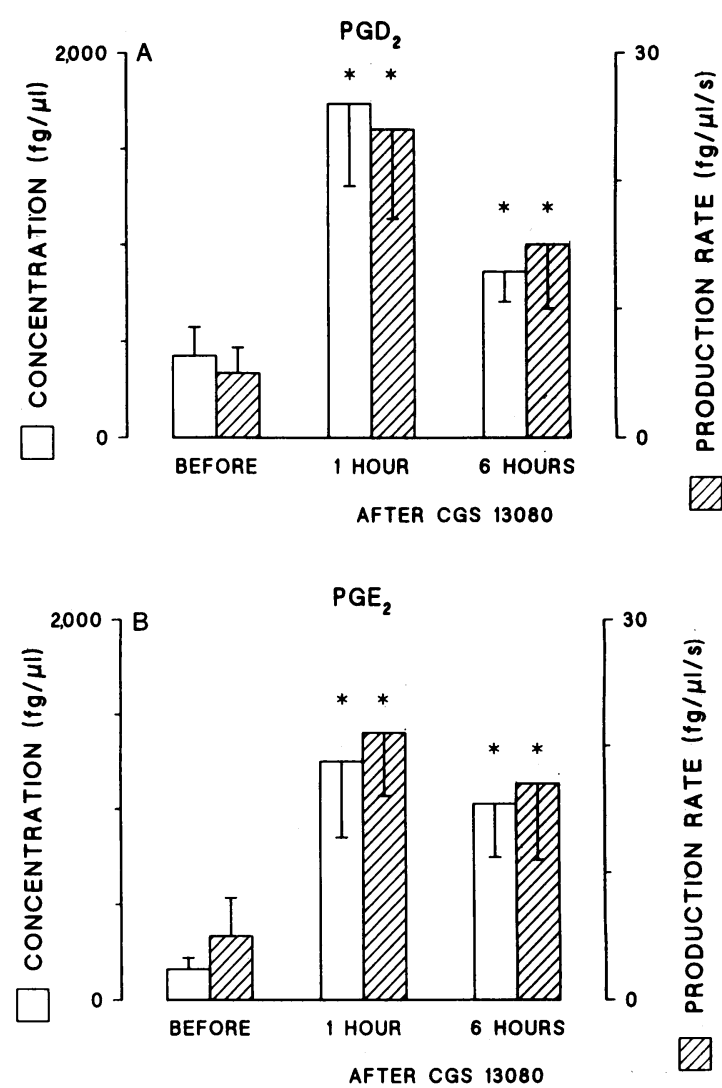

Figure 4. Formation of $\mathrm{PGD}_{2}(A)$ and $\mathrm{PGE}_{2}(B)$ in bleeding time blood before and after administration of a TX synthase inhibitor (CGS 13080). Data are expressed both as an absolute concentration and a production rate. Differences from measurements performed before drug administration are indicated as $* *=P<0.01$.

grees of antibody cross-reactivity can rësult in substantial errors of quantitation when endoperoxide rediversion is assessed after TX synthase inhibition in whole blood in vitro (27). In addition, this approach provided the sensitivity sufficient to assay several eicosanoids in multiple aliquots over the course of the bleeding time. Thus, the demonstration of com-

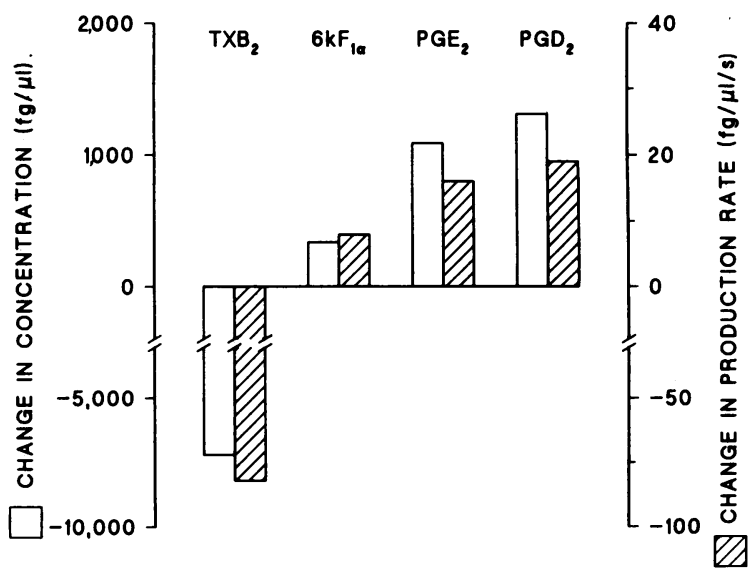

Figure 5. Mean $(n=6)$ changes in eicosanoid formation in bleeding time blood from pretreatment levels, $1 \mathrm{~h}$ after administration of the TX synthase inhibitor, CGS 13080 . Data are expressed both as absolute concentrations and production rates. 
Table I. TX Formation and Bleeding Time after Administration of the TX Synthase Inhibitor, CGS 13080, to Six Healthy Volunteers

\begin{tabular}{lccc}
\hline & & \multicolumn{2}{c}{ Postdosing } \\
\cline { 3 - 4 } & Predrug & $1 \mathrm{~h}$ & $6 \mathrm{~h}$ \\
\hline Serum $\mathrm{TXB}_{2}(\mathrm{ng} / \mathrm{ml})$ & $375 \pm 102$ & $3 \pm 1^{*}$ & $126 \pm 29^{\ddagger}$ \\
Bleeding time $(s)$ & $404 \pm 63$ & $445 \pm 55$ & $398 \pm 41$ \\
Bleeding time blood & & & \\
$\quad$ volume $(\mu l)$ & $231 \pm 66$ & $254 \pm 49$ & $312 \pm 101$ \\
Urinary 2,3-dinor-TXB & $108 \pm 29$ & $43 \pm 12^{\ddagger}$ & \\
& & &
\end{tabular}

${ }^{*} P<0.01 ;{ }^{\ddagger} P<0.05$. Differences expressed reflect two-tailed comparisons with predosing values (Wilcoxon signed rank test). Urine was collected for measurement of 2,3-dinor- $\mathrm{TXB}_{2}$ in 2-h aliquots before and after dosing.

parable time courses of $\mathrm{TXB}_{2}$ formation before, and that of other eicosanoids after TX synthase inhibition was dependent upon this methodology.
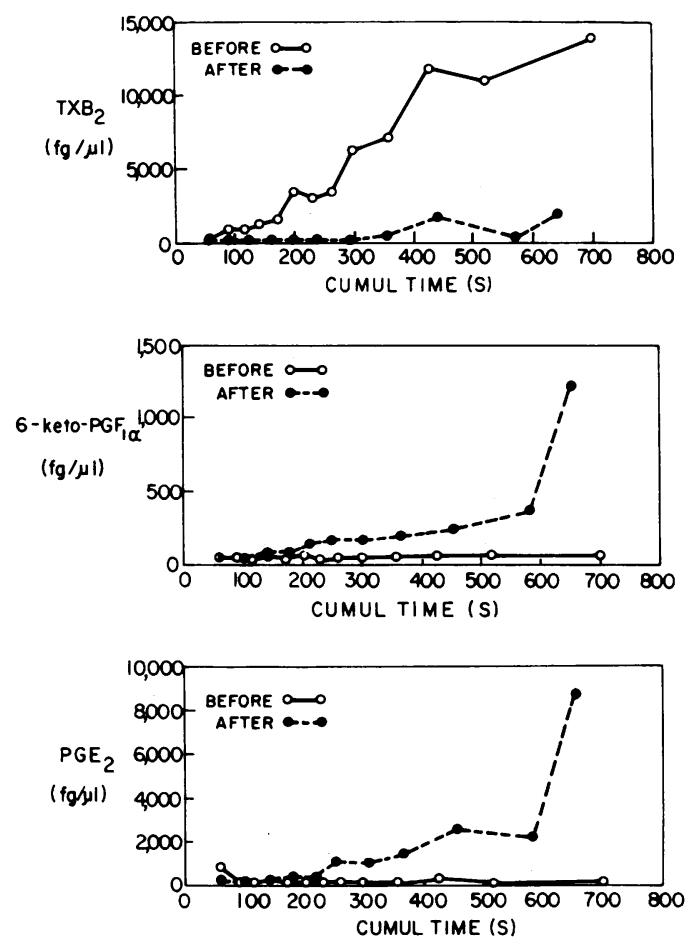

Figure 6. The temporal patterns of formation of $\mathrm{TXB}_{2}$ and 6-keto$\mathrm{PGF}_{1 \alpha}$ in the same individual before (0) and $1 \mathrm{~h}$ after $(\bullet)$ administration of the TX synthase inhibitor CGS 13080. This is a different individual from those depicted in Figs. 1 and 2. Data are expressed as actual concentrations rather than rate (which gives qualitatively similar results) for convenience of display. Cumulative time during which blood emerged from the skin incision is expressed on the abscissa. The increases in 6-keto-PGF ${ }_{1 \alpha}$ and $\mathrm{PGE}_{2}$ formation early in the bleeding time, before administration of the inhibitor, are obscured by the compression of the scales necessary to demonstrate the drug-related rise in eicosanoid concentrations. Note how the temporal pattern of augmented 6-keto-PGF ${ }_{1 \alpha}$ formation after CGS 13080 resembles that of $\mathrm{TXB}_{2}$ before drug administration.
Quantitative analysis of the decrease in $\mathrm{TXB}_{2}$ production and the increment in 6-keto- $\mathrm{PGF}_{1 \alpha}, \mathrm{PGE}_{2}$, and $\mathrm{PGD}_{2}$ formation suggest that reusing PG endoperoxides is a relatively, albeit not completely, efficient process (Fig. 5). Although we cannot definitively address the cellular origin of the eicosanoids measured in bleeding time blood, several observations seem appropriate. First, $\mathrm{PGE}_{2}$ is a much more abundant product of endoperoxide rediversion than 6-keto-PGF PG $_{1 \alpha}$. Although both platelets and monocytes possess a minor capacity to generate this eicosanoid, $\mathrm{PGE}_{2}$ rather than $\mathrm{PGI}_{2}$ is the major eicosanoid formed by microvascular endothelial cells of rabbit coronary and human foreskin origin in culture $(28,29)$. Secondly, although bovine coronary microvessels possess $\mathrm{PGD}_{2}$ isomerase, platelets also have a considerable capacity to generate this eicosanoid (30). Thus, the quantitatively impressive formation of $\mathrm{PGD}_{2}$ after TX synthase inhibition may reflect reorientation of endoperoxide metabolism within a single cell type, the platelet, although vascular production cannot be discounted.

Evidence of the likely functional importance of platelet-inhibitory PG in the antithrombotic action of TX synthase inhibitors has recently been provided. TX synthase inhibitors have been shown to have synergistic effects with antagonists of the shared PG endoperoxide/TXA $\mathrm{T}_{2}$ receptor both in the prevention of electrically induced coronary artery thrombosis (31) and in the abolition of platelet-dependent cyclical flow phenomena in an experimental model of partial coronary occlusion (32). In both instances synergy was abolished by pretreatment with a cyclooxygenase inhibitor, suggesting its dependence on the generation of platelet-inhibitory eicosanoids, such as $\mathrm{PGI}_{2}$ and $\mathrm{PGD}_{2}$.

Study of the formation of eicosanoids in bleeding time blood also provides insight into their potential role at sites of vascular injury under physiological conditions, the temporal increase of $\mathrm{TXB}_{2}$ in bleeding time blood coincides with the phase of platelet-platelet interaction after vascular injury in the rat mesentery (33). This would be consistent with other platelet agonists, such as ADP, being of primary importance during the initial phase of platelet recruitment at the site of vascular damage. Thus, TXA $_{2}$ might serve predominantly as an amplifying mechanism, analogous to its role in the "secondary" wave of ADP-initiated platelet aggregation in vitro. After the disruption of the integrity of the endothelium in the rat mesentery there is a rapid deposition of platelets that is localized to the site of the vascular injury. This is followed by the further deposition of platelets to overlay the initial monolayer (33). The earlier increase in $\mathbf{P G I}_{2}$ formation corresponds in time to the phase of platelet-vessel wall interaction, suggesting that this eicosanoid may play a homeostatic role in limiting the extent of platelet accumulation. In keeping with this hypothesis, the quantity of $\mathrm{PGI}_{2}$ detected in bleeding time blood is sufficient to inhibit platelet function. For example, studies performed in vitro indicate that the threshold concentration for an effect of $\mathrm{PGI}_{2}$ on platelets is $\sim 30 \mathrm{fg} / \mu \mathrm{l}$, in excess of the concentrations $(<3 \mathrm{fg} / \mu \mathrm{l})$ estimated to circulate under physiological circumstances in man (2-5). By contrast, peak concentrations averaged $305 \mathrm{fg} / \mu$ l during the bleeding time. Thus, biologically effective concentrations of this eicosanoid are formed at the site of vascular injury in man.

Despite this augmentation in $\mathrm{PGI}_{2}$ formation it is noteworthy that the bleeding time was only modestly prolonged after administration of the TX synthase inhibitor (Table I). Al- 
though interpretation of these data must be limited by the possibility of artifact due to blood sampling, this is not an unexpected finding $(16,21,34,35)$. Indeed, sample collection might have been expected to prolong rather than shorten the bleeding time due to disturbance of hemostatic plug formation. This may imply that TX generation is of little importance in the control of hemorrhage. However, many factors influence the bleeding time and the explanation for this phenomenon was not addressed in the present study. However, in addition to their availability for further metabolism, PG endoperoxides may substitute for the action of $\mathrm{TXA}_{2}$ at their shared receptor(s) after administration of TX synthase inhibitors (13, 16). Such an effect would be expected to limit the ability of such compounds to prolong the bleeding time.

In conclusion, we report the development of a microquantitative analytical technique that permits the precise and sensitive characterization of eicosanoid formation at the plateletvascular interface. $\mathrm{PGI}_{2}$ is generated locally in biologically effective concentrations after vascular injury. Furthermore, administration of a TX synthase inhibitor results in reorientation of PG endoperoxide metabolism, further augmenting $\mathrm{PGI}_{2}$ generation at the platelet-vascular interface in man. However, the biological effects of these compounds are likely to reflect the augmented production of other eicosanoids such as $\mathrm{PGE}_{2}$ and $\mathrm{PGD}_{2}$ in addition to $\mathrm{PGI}_{2}$. This approach can be readily applied to further study of the transcellular metabolism of eicosanoids in man.

\section{Acknowledgments}

This work was supported by grant HL-30400 from the National Institutes of Health. Dr. FitzGerald is an Established Investigator of the American Heart Association.

\section{References}

1. Bunting, S., R. Gryglewski, S. Moncada, and J. R. Vane. 1976. Arterial walls generate from prostaglandins endoperoxides a substance (prostaglandin $\mathrm{X}$ ) which relaxés strips of mesenteric and coeliac arteries and inhibits platelet aggregation. Prostaglandins. 12:897-913.

2. Christ-Hazelhof, E., and D. H. Nugteren. 1981. Prostacyclin is not a circulating hormone. Prostaglandins. 22:739-746.

3. FitzGerald, G. A., A. R. Brash, P. Falardeau, and J. A. Oates. 1981. Estimated rate of prostacyclin secretion into the circulation of normal man. J. Clin. Invest. 68:1272-1275.

4. Siess, W., and F. Dray. 1982. Very low levels of 6-keto-prostaglandin $\mathrm{F}_{1 \alpha}$ in human plasma. J. Lab. Clin. Med. 99:388-398.

5. Blair, I. A., S. E. Barrow, K. A. Waddell, P. J. Lewis, and C. T. Dollery. 1982. Prostacyclin is not a circulating hormone in man. Prostaglandins. 23:579-589.

6. Weksler, B. B., C. W. Ley, and E. A. Jaffe. 1978. Stimulation of endothelial cell prostacyclin production by thrombin, trypsin and the ionophore A-23187. J. Clin. Invest. 62:923-930.

7. Coughlin, S. R., M. A. Moskowitz, B. R. Zetter, H. N. Antoniades, and L. Levine. 1980. Platelet dependent stimulation of prostacyclin synthesis by platelet derived growth factor. Nature (Lond.). 288:600-602.

8. McIntrye, T. M., G. A. Zimmerman, K. Satoh, and S. M. Prescott. 1985. Cultured endothelial cells synthesize both platelet-activating factor and prostacyclin in response to histamine, bradykinin, and adenosine triphosphate. J. Clin. Invest. 76:271-280.
9. FitzGerald, G. A., B. Smith, A. K. Pedersen, and A. R. Brash. 1986. Increased prostacyclin biosynthesis in patients with severe atherosclerosis and platelet activation. N. Engl. J. Med. 310:1065-1068.

10. Fitzgerald, D. J., L. Roy, F. Catella, and G. A. FitzGerald. 1986. Platelet activation in unstable coronary disease. N. Engl. J. Med. 315:983-989.

11. Gorman, R. R., J. L. Bundy, D. C. Peterson, F. F. Sun, O. V. Miller, and F. A. Fitzpatrick. 1977. Inhibition of human platelet thromboxane synthetase by 9,11-azoprosta-5,13-dienoic acid. Proc. Natl. Acad. Sci. USA. 74:4007-4011.

12. Fitzpatrick, F. A., and R. R. Gorman. 1985. A comparison of imadazole and 9,11-azo-prosta-5,13-dienoic acid: two selective thromboxane synthetase inhibitors. Biochim. Biophys. Acta. 539:162172.

13. FitzGerald, G. A., I. A. G. Reilly, and A. K. Pedersen. 1985. The biochemical pharmacology of thromboxane synthase inhibition in man. Circulation. 72:1194-1201.

14. Marcus, A. J., B. B. Weksler, E. A. Jaffe, and M. J. Broekman. 1980. Synthesis of prostacyclin from platelet derived endoperoxides by cultured human endothelial cells. J. Clin. Invest. 66:979-986.

15. Schafer, A. I., D. D. Crawford, and M. A. Gimbrone. 1984. Unidirectional transfer of prostaglandin endoperoxides between platelets and endothelial cells. J. Clin. Invest. 73:1105-1112.

16. FitżGerald, G. A., A. R. Brash, J. A. Oates, and A. K. Pedersen. 1983. Endogenous prostacyclin biosynthesis and platelet function during selective inhibition of thromboxane synthesis in man. J. Clin. Invest. 72:1336-1343.

17. Wynalda, M. A., and F. A. Fitzpatrick. 1980. Albumins stabilize prostaglandin $\mathrm{I}_{2}$. Prostaglandins. 20:853-861.

18. Frangos, J. A., S. G. Eskin, L. V. McIntyre, and C. L. Ives. 1985. Flow effects on prostacyclin production by cultured human endothelial cells. Science (Wash. DC). 117:1477-1479.

19. FitzGerald, G. A., J. A. Oates, J. Hawiger, R. L. Maas, L. J. Roberts, and A. R. Brash. 1983. Endogenous synthesis of prostacyclin and thromboxane and platelet function during chronic aspirin administration in man. J. Clin. Invest. 71:676-688.

20. Nowak, J., J. J. Murray, J. A. Oates, and G. A. FitzGerald. 1987. Biochemical evidence of a chronic abnormality in platelet and vascular function in apparently healthy chronic cigarette smokers. Circulation. 76:6-14.

21. Reilly, I. A. G., J. Doran, B. Smith, and G. A. FitzGerald. 1986. Increased thromboxane biosynthesis in a human model of platelet activation: biochemical and functional consequences of selective inhibition of thromboxane synthase. Circulation. 73:1300-1309.

22. Moncada, S., and J. R. Vane. 1978. Unstable metabolites of arachidonic acid and their role in hemostasis and thrombosis. Br. Med. Bull. 34:129-136.

23. Needleman, P. 1979. Prostacyclin in blood vessel-platelet interactions: perspectives and questions. Nature (Lond.). 279:14-15.

24. Marcus, A. J. 1986. Transcellular metabolism of eicosanoids. In Progress in Hemostasis and Thrombosis. B. S. Coller, editor. Grune and Stratton, New York. 127-142.

25. Kyrle, P. A., H. G. Eichler, U. Jager, and K. Lechner. 1987. Inhibition of prostacyclin and thromboxane $A_{2}$ generation by low-dose aspirin at the site of plug formation in man in vivo. Circulation. 76:1025-1029.

26. Gresele, P., J. Arnout, H. Deckmyn, E. Huybrechts, G. Pieters, and J. Vermylen. 1987. Role of proaggregatory and antiaggregatory prostaglandins in hemostasis. Studies with combined thromboxane synthase inhibition and thromboxane receptor antagonism. J. Clin. Invest. 80:1435-1445.

27. Pedersen, A. K., M. Watson, and G. A. FitzGerald. 1983. Inhibition of thromboxane synthase in serum: limitations of the measurement of immunoreactive 6-keto-PGF F $_{1 \alpha}$. Thromb. Res. 33:99-103.

28. Gerritsen, M. E., and C. D. Cheli. 1984. Arachidonic acid and prostaglandin endoperoxide metabolism in isolated rabbit and coro- 
nary microvessels and isolated and cultivated coronary microvessel endothelial cells. J. Clin. Invest. 72:1658-1671.

29. Charo, I. F., S. Shak, M. A. Karasek, P. M. Davison, and I. M. Goldstein. 1984. Prostaglandin $I_{2}$ is not a major metabolite of arachidonic acid in cultured endothelial cells from human foreskin microvessels. J. Clin. Invest. 74:914-919.

30. Oelz, O., R. Oelz, H. R. Knapp, B. J. Sweetman, and J. A. Oates. 1977. Biosynthesis of prostaglandin $D_{2}$. I. Formation of prostaglandin $D_{2}$ by human platelets. Prostaglandins. 13:225-234.

31. Fitzgerald, D. J., J. Fragetta, and G. A. FitzGerald. 1988. Prostaglandin endoperoxides modulate the response to thromboxane synthase inhibition during coronary thrombosis. J. Clin. Invest. 82:17081713.
32. Shebuski, R. J. 1987. Effects of a thromboxane $A_{2}$ receptor antagonist alone and in combination with a thromboxane synthase inhibition on cyclic flow reductions in stenosed coronary arteries. Circulation. 76(Pt. II):100a. (Abstr.)

33. Born, G. V. R., and P. D. Richardson. 1980. Activation time of blood platelets. Gen. Membrane Biol. 57:87-90.

34. Vermylen, J., N. G. Defreyn, A. S. Carreras, S. J. Machin, J. V. Scaeren, and M. Verstraete. 1981. Thromboxane synthetase inhibition as an antithrombotic strategy. Lancet i:1073-1075.

35. Bertele, V., and G. De Gaetano. 1982. Potentiation by dazoxiben, a thromboxane synthetase inhibitor, of platelet aggregation inhibitory activity of a thromboxane receptor antagonist and of prostacyclin. Eur. J. Pharmacol. 85:331-336. 